\title{
ANÁLISE DE IMAGENS DIGITAIS PARA A AVALIAÇÃO DO COMPORTAMENTO DE PINTAINHOS DE CORTE
}

\section{MARCELO B. CORDEIRO ${ }^{1}$, ILDA F. F. TINÔCO², ROQUE M. DE MESQUITA FILHO ${ }^{3}$, FERNANDA C. DE SOUSA ${ }^{4}$}

\begin{abstract}
RESUMO: Na busca por respostas quanto às condições de bem-estar animal, visou-se a avaliar neste trabalho o comportamento de pintainhos nas duas primeiras semanas de vida, por meio de processamento de imagens digitais. $\mathrm{O}$ experimento foi realizado em dois galpões comerciais, utilizados para criação de 15.200 aves de corte por galpão, durante um ciclo produtivo, dotados com fornalha a lenha de aquecimento indireto do ar. Foram instaladas duas câmeras de vídeo por galpão para aquisição de imagens digitais. Uma das câmeras possuía inclinação angular de $45^{\circ}$, e a outra, inclinação angular de $90^{\circ}$ em relação ao solo. As imagens foram analisadas para cada condição climática diária e binarizadas, sendo depois processadas por meio de descritor de agrupamento/dispersão e correlacionadas com os valores de temperatura do ar. Observou-se correlação entre o descritor e os valores de temperatura do ar, sendo que as imagens obtidas pela câmera posicionada a $45^{\circ}$ e divididas em 25 blocos, obtiveram maior correlação. Pelos dados obtidos, pode-se observar que o comportamento de agrupamento e dispersão dos pintainhos pode ser usado como indicador dos estados de conforto térmico e que o descritor se mostrou eficiente para esta quantificação.
\end{abstract}

PALAVRAS-CHAVE: Comportamento animal, pintainhos de corte, processamento de imagens.

\section{DIGITAL IMAGE ANALYSIS FOR YOUNG CHICKEN'S BEHAVIOR EVALUATION}

ABSTRACT: The aim of this study was to evaluate the behavior of young chickens in the first two weeks of life through digital images processing, for the determination of the best condition of animal welfare. The experiment was accomplished at two buildings with furnace with indirect air heating, used for creation of 15,200 broiler chickens by building, during one single productive cycle. For the production of digital images, two video cameras were installed by building. One of the cameras had an inclination of $45^{\circ}$ and the other a $90^{\circ}$ in relation to the ground. The images were analyzed for each daily climatic condition. Then, they were binarized and processed through grouping/dispersion descriptor and correlated with the values of temperature of the air. Correlation was observed between the descriptor and the values of temperature of the air. Images obtained by the camera positioned at $45^{\circ}$ had the highest correlation. From the data obtained can be observed that the grouping/dispersion and the behavior of the young chickens can be used as indicator of the states of thermal comfort and that the descriptor was efficient for the quantification.

KEYWORDS: animal behavior, young chicken, image processing.

\footnotetext{
${ }^{1}$ Zootecnista, Doutor em Engenharia Agrícola, Universidade Federal de Viçosa, mbcordeiro@ gmail.com.

${ }^{2}$ Professor Associado, Departamento de Engenharia Agrícola, Universidade Federal de Viçosa, iftinoco@ufv.br.

${ }^{3}$ Estudante de Doutorado, Engenharia Agrícola, Universidade Federal de Viçosa, ambiagro@ufv.br.

${ }^{4}$ Estudante de Graduação, Engenharia Agrícola, Universidade Federal de Viçosa, ambiagro@ufv.br.

Recebido pelo Conselho Editorial em: 14-6-2010

Aprovado pelo Conselho Editorial em: 26-11-2010
} 


\section{INTRODUÇÃO}

O estudo do comportamento animal assume papel relevante dentro da produção avícola mundial, visto que impulsiona a adequação dos antigos métodos de criação às novas técnicas de manejo, alimentação e instalações. A caracterização do padrão e da estrutura do comportamento animal é uma tarefa importante para entender as interações complexas entre indivíduos e o meio em que vivem (HOCKING et al., 2007). O comportamento das aves é um parâmetro que pode mostrar o caminho para o desenvolvimento dos sistemas intensivos de produção no que se refere aos recentes padrões de bem-estar exigidos pelos principais países importadores de carne de frango.

Segundo XIN \& SHAO (2002), a avaliação e os controles interativos do conforto térmico dos animais pela análise de imagens superam os problemas inerentes ao método convencional, pois se utilizam dos próprios animais como biossensores em resposta aos reflexos do ambiente por meio de análise comportamental.

Vários estudos têm-se utilizado de técnicas de avaliação do comportamento de aves baseados em imagens (PEREIRA et al., 2005; BARBOSA FILHO et al., 2007; CORDEIRO, 2007; GERRITZEN et al., 2007; LEONE et al., 2007; MCKEEGAN et al., 2005; MARIA et al.,2004.). O objetivo da análise de imagens, seja por um observador humano, seja por visão computacional, é extrair informações úteis e relevantes para cada aplicação desejada (SERGEANT et al., 1998), não havendo, portanto, uma fórmula-padrão para todas as situações. Considerando que as aves na fase inicial da vida, mantidas sob condições térmicas de conforto, são mais ativas em relação às aves mais velhas e que condições adversas de temperatura afetam esse comportamento, o objetivo deste trabalho foi analisar e quantificar o comportamento de agrupamento/dispersão de pintainhos mantidos sob sistema de aquecimento, utilizando técnicas de processamento de imagens.

\section{MATERIAL E MÉTODOS}

O presente trabalho foi realizado em uma propriedade avícola comercial integrada da empresa Pif Paf Alimentos, no município de Viçosa - MG. Nesta pesquisa, foram utilizados dois galpões avícolas, dotados com sistema de aquecimento por fornalha a lenha de aquecimento indireto do ar, durante 1 ciclo produtivo completo, no período de julho a agosto de 2009.

O município de Viçosa está situado na latitude: $27^{\circ} 00^{\prime} 30^{\prime \prime}$ sul, longitude: $51^{\circ} 09^{\prime} 60^{\prime \prime}$ oeste, estando a uma altitude de $750 \mathrm{~m}$, possuindo clima temperado úmido, com temperatura média anual de 16 a $17^{\circ} \mathrm{C}$ e tipo climático (KÖEPPEN) Cfb - temperado (mesotérmico úmido e verão ameno.

Os galpões possuíam idênticas dimensões $(12,0 \times 150,0 \times 3,0 \mathrm{~m})$, mesmas características construtivas e mesma orientação, distanciados 50,0 m uns dos outros. Os galpões possuíam forros de poliuretano, posicionados a $3 \mathrm{~m}$ de altura, muretas laterais com $0,10 \mathrm{~m}$ de altura e laterais teladas protegidas por duplo cortinado de poliuretano. A cobertura era composta com telhas de barro, com inclinação de $30 \%$ e beiral de $0,50 \mathrm{~m}$. Os aviários eram equipados com o mesmo número de comedouros e de bebedouros, sendo estes da mesma marca e modelo, e distribuídos uniformemente em toda a área dos galpões. O manejo zootécnico adotado foi idêntico nos dois galpões e correspondeu ao usual praticado pelos produtores integrados da empresa.

No experimento, foram utilizadas 15.200 aves de corte, por galpão, originadas do incubatório da própria empresa. Todo o processo de embarque e desembarque das aves obedeceu ao mesmo procedimento e horário para todos os galpões. As dietas fornecidas aos animais foram formuladas com base nas exigências de nutrientes para as diferentes fases de crescimento, estabelecidas pelo setor de agropecuária da empresa e foram iguais para todos os tratamentos.

$\mathrm{Na}$ fase inicial, duas primeiras semanas de vida, as aves foram confinadas numa área correspondente a $1 / 3$ do total do galpão. Este espaço, denominado pinteiro, foi protegido com cortinas de lona plástica para reduzir o espaço a ser aquecido e fez-se a ampliação desta área a cada semana de vida das aves, até que, em 3 semanas de idade, o pinteiro, então ampliado à $1 \frac{1}{2}$ do galpão, foi desfeito, e todo o aviário foi ocupado pelas aves adultas. 
A fornalha a lenha de aquecimento indireto do ar adotado nos dois galpões era constituída por corpo em formato cilíndrico, construída em material metálico e revestida por material isolante térmico. Apresentava na área interna central uma câmara de combustão, sendo formada uma área para passagem do fluxo de ar no espaço entre a parede interna da fornalha e a superfície da câmara de combustão. $\mathrm{O}$ ar era injetado na fornalha através de sucção de uma turbina localizada na extremidade oposta à abertura da fornalha. A turbina, movida por um motor elétrico, conduzia o fluxo de ar aquecido à saída da fornalha e posteriormente para um sistema de distribuição de ar aquecido composto por tubulação metálica colocada na parte interna central do galpão. A tubulação possuía orifícios para a saída do ar aquecido a cada $1,0 \mathrm{~m}$. O controle na temperatura interna era realizado por meio de termistor conectado a um painel, que controlava o acionamento do ventilador e, consequentemente, a velocidade da queima e a vazão de ar aquecido que entrava no galpão.

Para caracterizar o ambiente térmico, foram tomadas as medidas de temperatura do ar e umidade relativa do ar em três pontos medianos de cada galpão. As medições foram realizadas a uma altura compatível com a zona de ocupação dos pintainhos, a 10,0 cm da cama, em intervalos de 15 minutos, durante todo o período experimental. Foram utilizados dataloggers T/HR da marca Testo, modelo $\mathrm{H} 1$, com resolução de $0,1^{\circ} \mathrm{C}$ (temperatura) e $1 \%$ (umidade), e acurácia de $\pm 0,5{ }^{\circ} \mathrm{C}$ (temperatura) e $\pm 1 \%$ (umidade). Sendo os galpões de mesmas dimensões e mesmas características construtivas, os pontos de medições dos galpões foram equivalentes.

Foram instaladas duas câmeras de vídeo em cada galpão avícola, conectadas a um microcomputador equipado com software para aquisição e armazenamento das imagens. As duas câmeras de vídeo foram posicionadas no cortinado superior ao pinteiro, a 3,0 m de altura na linha dos tirantes da tesoura. Uma das câmeras foi instalada com inclinação de $45^{\circ}$, e a outra, com inclinação de $90^{\circ}$ em relação ao solo. As câmeras eram da marca PROJECT SYSTEM, com sensores CCD 1/4" SHARP, resolução de imagem de 510(H) x 492(V) pixels, lente de 3,6 mm de distância focal e iluminação mínina requerida de 0,3 Lux.

Foi registrada uma imagem a cada intervalo de 15 segundos. Os horários de registros das imagens foram das $8 \mathrm{~h}$ às $18 \mathrm{~h}$ durante o período experimental, compreendendo a primeira e a segunda semanas de vida das aves. As imagens foram capturadas somente durante o dia, quando havia condições ideais de luminosidade. Foram excluídas manualmente imagens que representassem comportamento causado por fatos isolados (barulhos externos, entrada de pessoas nas instalações, entre outros).

O estudo e as definições de padrões do comportamento animal foram realizados com base na análise e processamento de imagens digitais. Os algoritmos para a identificação dos animais e a obtenção dos descritores foram implementados no programa computacional MATLAB ${ }^{\circledR}$ R12. A representação esquemática das etapas do processamento das imagens pode ser visualizada na Figura 1.

Para estudar o comportamento dos pintainhos, foram utilizados descritores da forma de agrupamento e dispersão, semelhantes aos utilizados por CORDEIRO (2007). Neste descritor, as imagens binarizadas foram divididas em blocos ( 25 blocos, 100 blocos e 225 blocos). Em seguida, foi calculado o desvio-padrão da soma dos valores dos pixels de cada bloco. Para avaliar a eficiência desse descritor, foi feita a correlação entre o desvio-padrão e a temperatura do ar. 


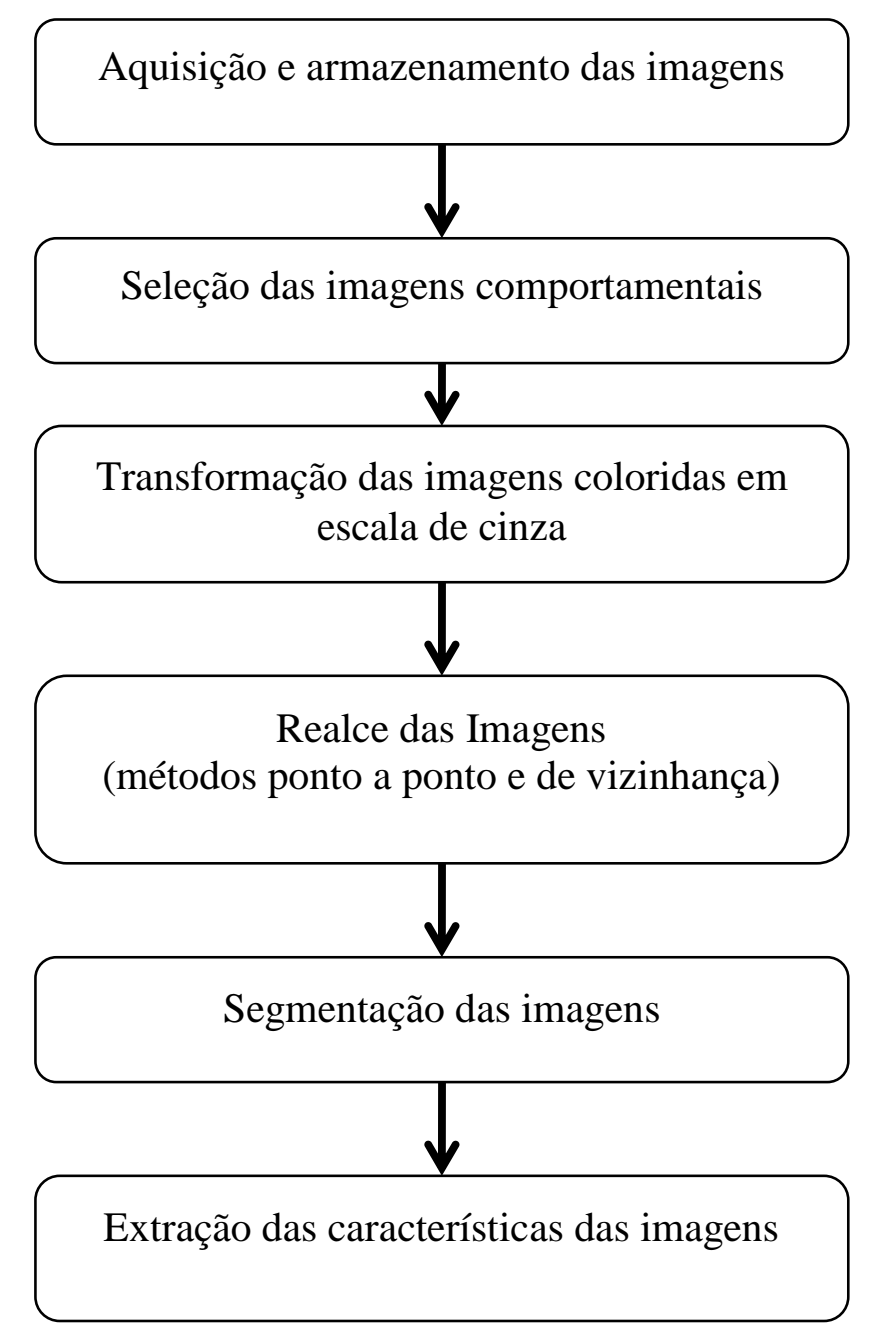

FIGURA 1. Representação esquemática das etapas do processamento das imagens. Schematic representation of the image processing stages.

Para estudar o comportamento dos pintainhos, foram utilizados descritores da forma de agrupamento e dispersão, semelhantes aos utilizados por CORDEIRO (2007). Neste descritor, as imagens binarizadas foram divididas em blocos (25 blocos, 100 blocos e 225 blocos). Em seguida, foi calculado o desvio-padrão da soma dos valores dos pixels de cada bloco. Para avaliar a eficiência desse descritor, foi feita a correlação entre o desvio-padrão e a temperatura do ar.

\section{RESULTADOS E DISCUSSÃO}

Nas Figuras 2 e 3, estão apresentados os valores médios horários da temperatura do ar $\left(\mathrm{C}^{0}\right)$, observados no interior das instalações avícolas, para a primeira e segunda semanas de vida dos pintainhos, em função dos horários de observação. 


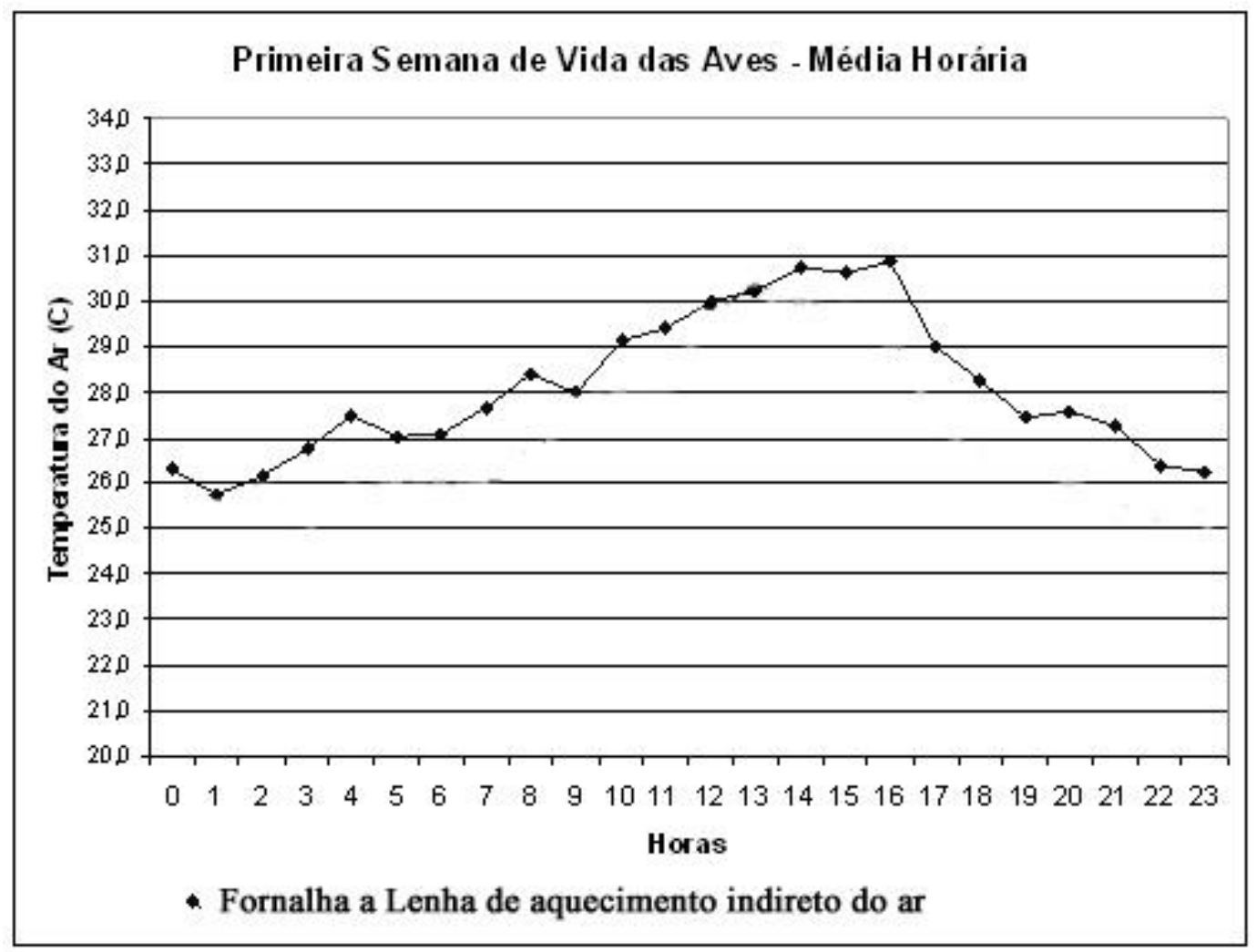

FIGURA 2. Valores médios horários da temperatura do $\operatorname{ar}\left(\mathrm{C}^{\mathrm{o}}\right)$, para a primeira semana de vida das aves. Hourly average values of air temperature $\left(C^{0}\right)$, for the first week of the birds life.

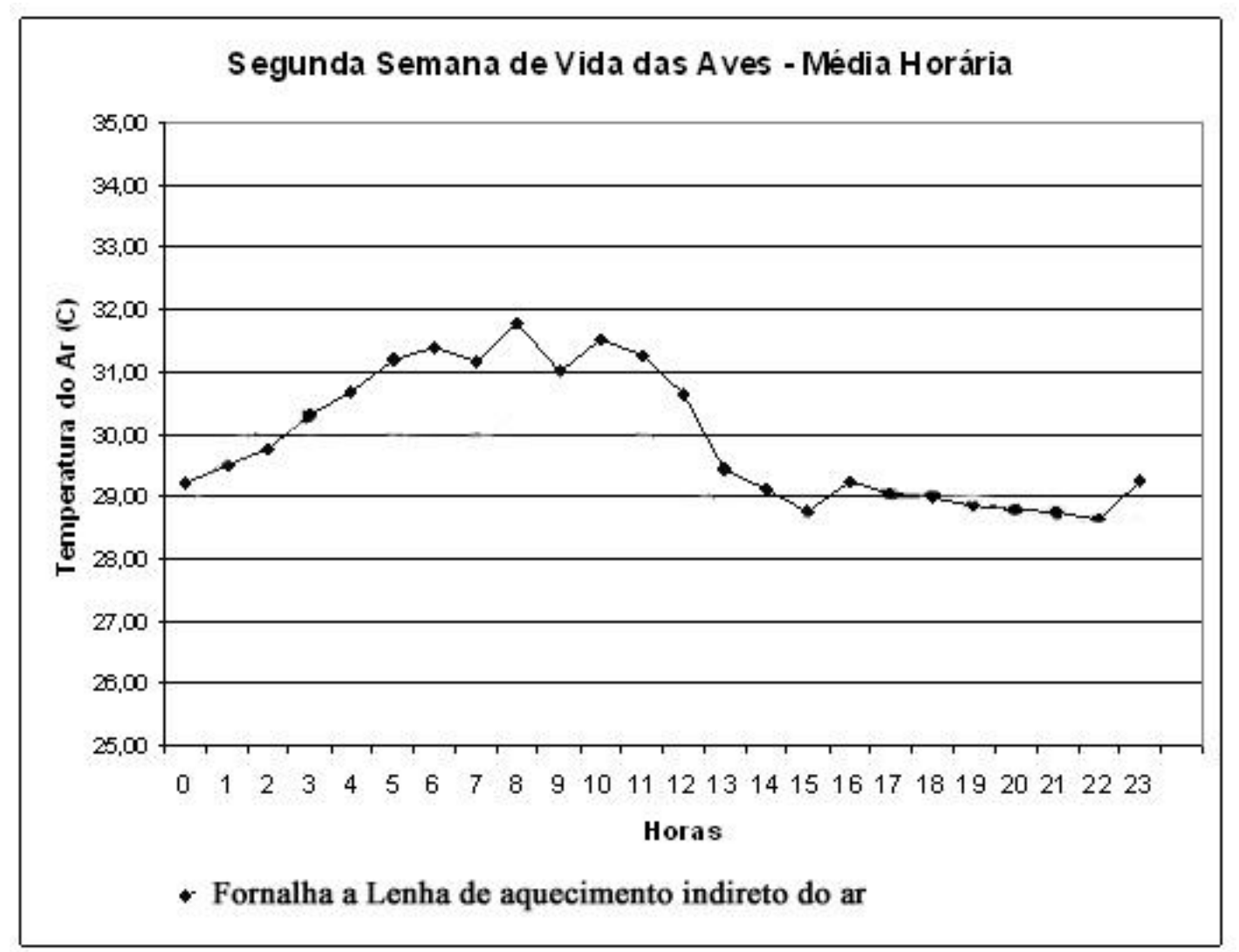

FIGURA 3. Valores médios horários da temperatura do ar $\left(\mathrm{C}^{\circ}\right)$, para a segunda semana de vida das aves. Hourly average values of air temperature $\left(C^{0}\right)$, for the second week of birds life. 
Verifica-se que, na primeira semana de vida das aves, o sistema de aquecimento não conseguiu proporcionar calor suficiente para manter os pintainhos sob condições de conforto térmico, que, segundo MACARI et al. ( 2002), situam-se entre $32-34{ }^{\circ} \mathrm{C}$. Na segunda semana de vida das aves, o sistema de aquecimento manteve os pintainhos sob condições de conforto térmico, recomendada por MACARI et al. (2002) como sendo a faixa de valores de temperaturas do ar situada entre $28-32{ }^{\circ} \mathrm{C}$.

O sistema de aquecimento de fornalha a lenha por queima indireta, de forma geral, mostrou-se aceitável para proporcionar aquecimento satisfatório para os pintainhos nas duas primeiras semanas de vida. Essa fase é considerada crítica para as aves, pois os pintainhos são mais suscetíveis às situações de estresse, podendo sofrer comprometimento do sistema imunológico, ficando vulneráveis a doenças e, por conseguinte, apresentando rendimento produtivo menor que o esperado. Pereira et al. (2005) verificaram a influência direta do ambiente térmico no comportamento de aves, demonstrando a viabilidade de buscar indicadores de bem-estar baseados no comportamento animal.

Para avaliar o comportamento dos pintainhos, as imagens selecionadas foram transformadas em escala de cinza, realçadas, e logo após, binarizadas. O método da realce de imagem utilizada foi o ponto a ponto, através da modificação do histograma e da modificação de contraste. $O$ realce visou a melhorar a qualidade da imagem, permitindo melhor discriminação dos pintainhos presentes na imagem. No interior dos galpões, há intensa variação de luminosidade durante o dia, podendo causar, com isso, baixo contraste em determinadas regiões da imagem, o qual dificultaria o processamento desta imagem.

$\mathrm{Na}$ binarização, as aves foram representadas com pixels de valor 1 (branco), e o restante do constituinte da imagem (bebedouro, comedouro, cama), representada com pixels de valor 0 (preto). Cada uma das imagens binarizadas foi associada a um valor de temperatura do ar para cada dia de vida das aves, durante as duas primeiras semanas de vida.

Na Figura 4, estão apresentadas as imagens em escala de cinza (a) e binarizadas (b) para as câmeras posicionadas num ângulo de $90^{\circ}$ em relação ao solo. Na Figura 5, estão apresentadas as imagens em escala de cinza (a) e binarizadas (b) para as câmeras posicionadas num ângulo de $45^{\circ}$ em relação ao solo.

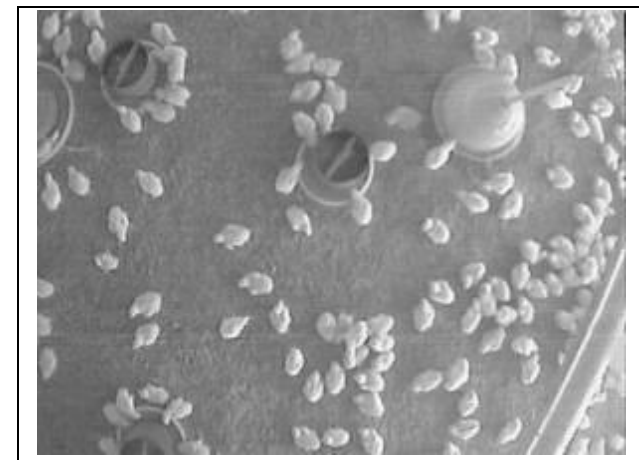

(a)

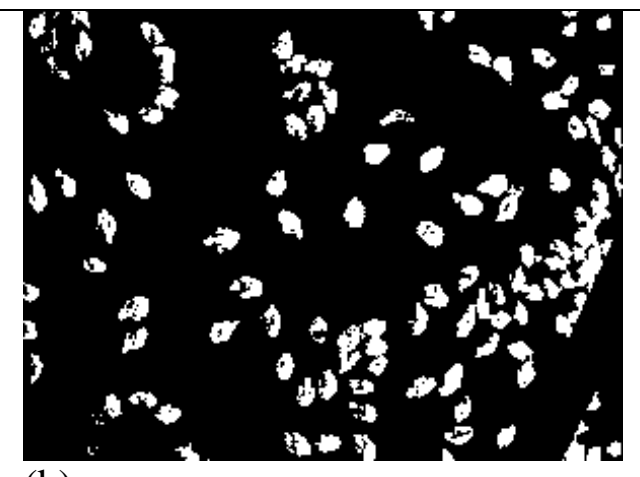

(b)

FIGURA 4. Imagens em escala de cinza (a) e limiarizadas (b), para as câmeras posicionadas num ângulo de $90^{\circ}$ em relação ao solo, com os pintainhos representados em branco. Grayscale images (a) and threshold (b), for the cameras positioned at an angle of $90^{\circ}$ to the ground with the chicks represented in white. 


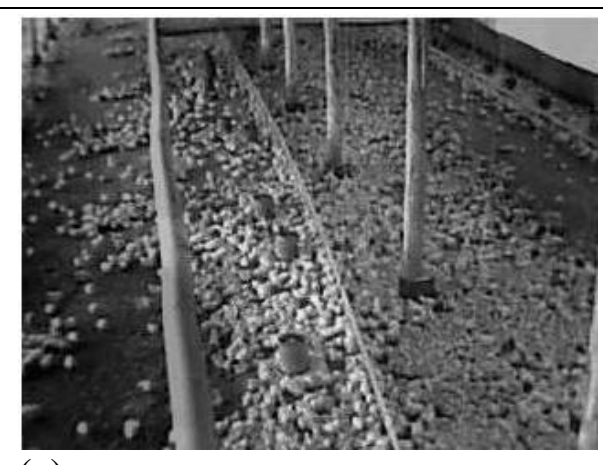

(a)

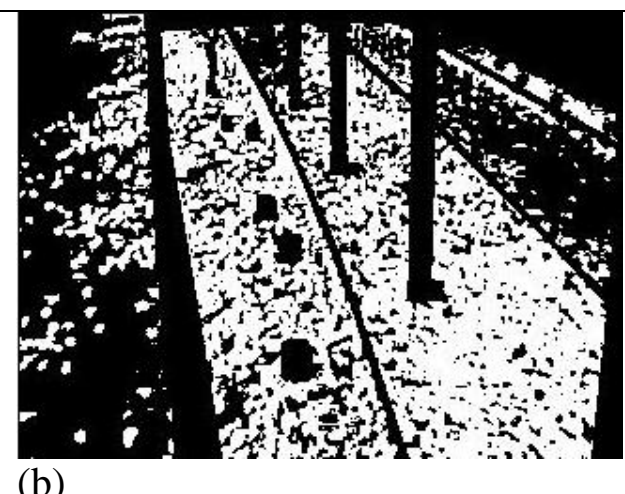

(b)

FIGURA 5. Imagens em escala de cinza (a) e limiarizadas (b), para as câmeras posicionadas num ângulo de $45^{\circ}$ em relação ao solo, com os pintainhos representados em branco. Grayscale images (a) and threshold (b), for the cameras positioned at an angle of $45^{\circ}$ to the ground with the chicks represented in white.

Na Figura 6, estão apresentadas as imagens binárias do experimento, divididas em 25; 100 e 225 blocos.
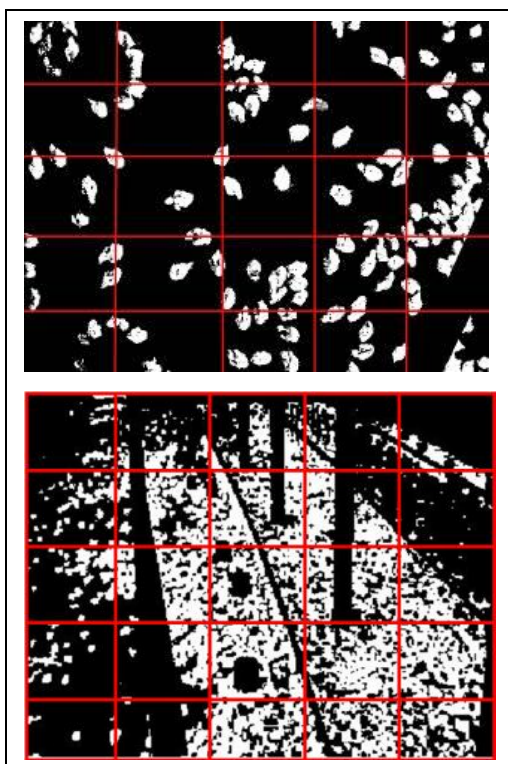

(a)
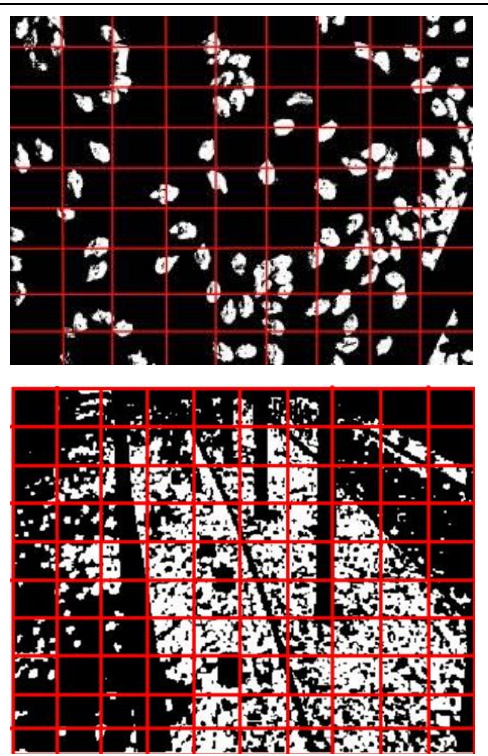

(b)
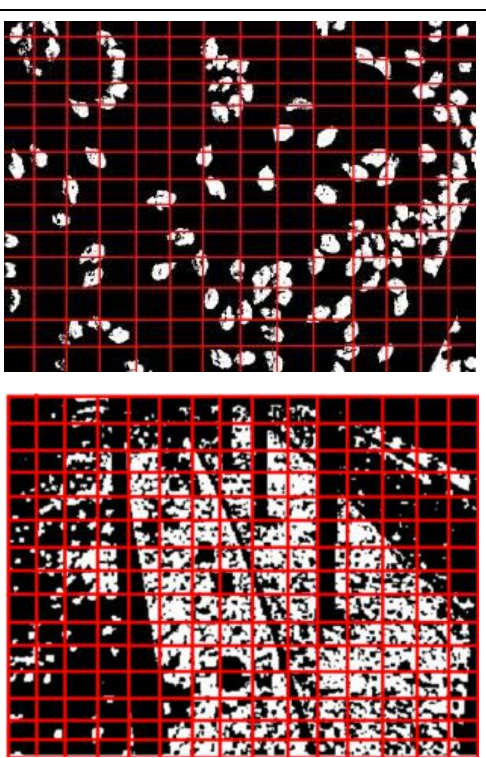

(c)

FIGURA 6. Imagens binárias divididas em 25 blocos (a), 100 blocos e 225 blocos (c), respectivamente. Binary images divided into 25 blocks (a), 100 blocks and 225 blocks (c), respectively.

A classificação dos estados de conforto térmico e das diversas condições de estresse por frio e por calor, depende do comportamento-padrão das aves em relação à dispersão e agrupamento das mesmas ao longo do galpão. As aves na primeira e na segunda semanas de vida tendem a se agrupar quando submetidas às condições de estresse por frio. Este comportamento ameniza a perda de calor sensível (radiação, convecção e condução), fazendo com que as aves mantenham sua homeostase. A dispersão das aves em condições de estresse por calor permite a melhor ventilação da superfície corporal e evita o recebimento de calor das outras aves, melhorando a perda de calor por radiação.

$\mathrm{Na}$ Tabela 1, estão apresentados os coeficientes de correlação referentes aos dados de temperatura do ar para cada dia de vida das aves, durante as duas primeiras semanas de vida, em função do desvio-padrão da soma dos pixels dos blocos das imagens, nos diferentes ângulos obtidos. 
TABELA 1. Coeficientes de correlação (r), dos valores de temperatura do ar para cada dia de vida das aves, durante as duas primeiras semanas de vida e do descritor de agrupamento/dispersão por divisão de blocos (25; 100 e 225) das imagens, nos diferentes ângulos das imagens. Correlation coefficients (r) of air temperature values during the first two weeks of life and of the clustering / dispersion descriptor by blocks division $(25,100,225)$ of the images in the different images angles.

\begin{tabular}{ccccc}
\hline \multirow{2}{*}{ Semanas de vida das aves } & Ângulos das & \multicolumn{2}{c}{ Coeficiente de Correlação (blocos) } \\
\cline { 3 - 5 } & imagens & 25 & 100 & 225 \\
\hline \multirow{2}{*}{$1^{\text {a }}$ semana } & $45^{\circ}$ & $-0,82^{* *}$ & $-0,59 * *$ & $-0,45^{* *}$ \\
& $90^{\circ}$ & $-0,73 * *$ & $-0,64 * *$ & $-0,61^{* *}$ \\
\hline \multirow{2}{*}{$2^{\text {a }}$ semana } & $45^{\circ}$ & $-0,94 * *$ & $-0,50 * *$ & $-0,28^{*}$ \\
& $90^{\circ}$ & $-0,74 * *$ & $-0,69 * *$ & $-0,57 *$ \\
\hline
\end{tabular}

* Significativo a $5 \%$ de probabilidade **Significativo a $1 \%$ de probabilidade

Observa-se, na Tabela 1, que a temperatura correlacionou-se significativamente aos valores de desvio-padrão da soma dos pixels da imagem. Esta correlação foi negativa, sendo que, com o decréscimo dos valores de temperatura, ocorre o aumento dos valores dos desvios-padrão.

Valores altos de desvios-padrão significam que existem blocos da imagem em que há alta concentração de aves e blocos com nenhuma ou muito pouca concentração de aves, indicando com isso forte grau de agrupamento, o que caracteriza estresse por frio e, consequentemente, baixos valores de temperatura do ar. Ou seja, quanto maior o desvio-padrão, menor a temperatura.

Observa-se também que houve diferença na correlação entre as divisões por blocos e entre as imagens com diferentes ângulos, sendo que os maiores coeficientes de correlação foram encontrados nas imagens com ângulo de $45^{\circ}$ e com 25 blocos. Com o maior número de divisões das imagens, a correlação foi diminuindo. Isso ocorreu devido ao fato de que, com a divisão das imagens em maior número de blocos, houve diminuição da área de cada bloco, aumentando o tamanho relativo de cada ave, dificultando a identificação da intensidade de concentração/dispersão. O bloco da imagem deve ser representativo do comportamento de um grupo de aves e não de uma ave, individualmente, nem de parte dela, o que aconteceu quando se dividiu a imagem em maior número de blocos. $\mathrm{O}$ foco dado para o estudo do comportamento varia com o tipo de análise a ser desenvolvida. FIGUEIREDO et al. (2003), avaliando comportamento de beber e comer de aves de corte, relataram problemas com agrupamentos contínuos de aves, sendo que o reconhecimento realizado pelo algoritmo desenvolvido identificou agrupamentos de aves como objetos contínuos e não como aves.

O posicionamento da câmera mostrou-se importante nos resultados encontrados e no tipo de abordagem dado ao estudo do comportamento. MOGAMI (2009), em experimento para determinação de massa corporal de frangos de corte por meio de análise digital, utilizou câmeras posicionadas perpendicularmente aos animais, encontrando forte correlação entre massa corporal e contagem binária dos frangos.

\section{CONCLUSÕES}

O descritor de agrupamento e dispersão proposto pode ser usado como indicativo de conforto e desconforto térmico de pintainhos de corte na primeira e segunda semanas de vida.

As imagens adquiridas com inclinação angular de $45^{\circ}$ e a divididas em 25 blocos obtiveram maiores coeficientes de correlação com a temperatura.

O bloco da imagem deve ser representativo do comportamento de um grupo de aves e não de uma ave individualmente, nem de parte dela, o que aconteceu quando se dividiu a imagem em maior número de blocos. 


\section{AGRADECIMENTOS}

À FAPEMIG, pelo apoio na realização deste trabalho através de concessão de bolsa de pós-doutorado.

Ao CNPq, à CAPES, à Universidade Federal de Viçosa e ao Departamento de Engenharia Agrícola, pelo apoio à pesquisa.

\section{REFERÊNCIAS}

BARBOSA FILHO, J.A.D.; SILVA, I..J.O.; SILVA, M.A.N.; SILVA, C.J.M. Avaliação dos comportamentos de aves poedeiras utilizando sequência de imagens. Engenharia Agrícola, Jaboticabal, v.27, n.1, p.93-99, 2007.

CORDEIRO, M.B. Análise de imagens na avaliação do comportamento, do bem-estar e do desempenho de pintos de corte submetidos a diferentes sistemas de aquecimento. 2007. $111 \mathrm{f}$. Tese (Doutorado em Engenharia Agrícola) - Universidade Federal de Viçosa, Viçosa, 2007.

FIGUEIREDO , G.F.; DICKERSON, T.W.; BENSON, E.R.; VAN WICKELEN, G.L.; GEDAMU, N. Development of machine vision based poultry behavior analysis system. Las Vegas: ASAE Metting, 2003. (Paper, 033083).

GERRITZEN, M.; LAMBOOIJ, B.; REIMERT, H.; STEGEMAN, A.; SPRUIJT, B. A note on behaviour of poultry exposed to increasing carbon dioxide concentrations. Applied Animal Behaviour Science, Amsterdam, v.108, p.179-185, 2007.

HOCKING, P.M.; RUTHERFORD, K.M.D.; PICARD, M. Comparison of time-based frequencies, fractal analysis and T-patterns for assessing behavioural changes in broiler breeders fed on two diets at two levels of feed restriction: A case study. Applied Animal Behaviour Science, Amsterdam, v.104, p.37-48, 2007.

LEONE, E.H.; ESTEVEZ, I.; CHRISTMAN, M.C. Environmental complexity and group size: Immediate effects on use of space by domestic fowl. Applied Animal Behaviour Science, Amsterdam, v.102, p.39-52, 2007.

MACARI, M.; FURLAN, R. L.; GONZÁLES, E. (Ed.). Fisiologia aplicada a frangos de corte. Jaboticabal: FUNEP/UNESP, 2002. 375 p.

MARÍA, G.A.; ESCÓS, J.; ALADOS, C.L. Complexity of behavioural sequences and their relation to stress coinditions in chickens (Gallus gallus domesticus): a non-invasive technique to evaluate animal welfare. Applied Animal Behavior Science, Amsterdam, v.86, n.1, p.93-104, 2004.

MCKEEGAN, D.E.F.; MCINTYRE, J.; DEMMERS, T.G.M.; WATHES, M.; JONES, R.B. Behavioural responses of broiler chickens during acute exposure to gaseous stimulation. Applied Animal Behaviour Science, Amsterdam, v.99, p.271-286, 2005.

MOGAMI, C.A. Desenvolvimento de metodologias para determinaçào do bem-estar e massa corporal de frangos de corte por meio de análise digital de imagens. 2009. $101 \mathrm{f}$. Dissertação (Doutorado) - Universidade Federal de Viçosa, Viçosa, 2009.

PEREIRA, D.F.; NÄÄS, I.A.; ROMANINI, C.B.; SALGADO, D.D.; PEREIRA, G.O.T. Indicadores de bem-estar baseados em reações comportamentais de matrizes pesadas. Engenharia Agrícola, Jaboticabal, v.25, n.2, p.308-314, 2005.

SERGEANT, D.; BOYLE, R.; FORBES, M. Computer visual tracking of poultry. Computers and Electronics in Agriculture, New York, v 21, p.1-18, 1998.

XIN, H.; SHAO, J. Real time assessment of swine thermal comfort by computer vision. In: WORLD CONGRESS OF COMPUTERS IN AGRICULTURE AND NATURAL RESOURCES, 2., 2002, Foz do Iguaçu. Procedings... Foz do Iguaçu: ASAE, 2002. p.362-369. 